\author{
I. Istadi (Editor-in-Chief) \\ Department of Chemical Engineering, Diponegoro University, E-mail: istadi@che.undip.ac.id
}

DOI: $10.9767 /$ bcrec.12.1.942.v-vii

Bulletin of Chemical Reaction Engineering \& Catalysis, (e-ISSN: 1978-2993), is an international journal published by Department of Chemical Engineering, Diponegoro University, jointly with Masyarakat Katalis Indonesia - Indonesian Catalyst Society (MKICS). In Scopus coverage years 20112015, this journal was ranked 38 th (Q4 level) in Scimago for Catalysis category and ranked 29th (Q4 level) in Scimago for Process and Chemistry Technology category. In addition, this journal has also a good impact factor in Scimago Journal Ranking / Journal Metrics $(\mathrm{SJR}=0.192 ; \mathrm{SNIP}=0.477$; IPP $=$ 0.533 ) and has Cite Score $=0.54$ in Scopus for coverage years 2011-2015. Since 2015, this journal has also been listed in Master Journal List of Thomson Reuters-Web of Science Core Collection Database (Emerging Source Citation Index), and under evaluation to be indexed in Science Citation Index Expanded (to be included in Journal Citation Report (JCR)). Thank you for the great contribution to all respectful Authors, Peer-reviewers, and Editors.

This issue (Bull. Chem. React. Catal. Eng., Volume 12, Issue 1, Year 2017 (April) has published 16 original research articles. This issue was authored and co-authored by 63 authors from 9 countries (Indonesia, Malaysia, Iran, China, India, South Africa, Saudi Arabia, Brunei Darussalam, and Pakistan). This issue has available online since 13 February 2017 for the regular issue of April 2017.

In this issue, there were three articles concerned on nanomaterials or nanocatalysts. The first article was focused on electrosynthesized Ni-Al layered double hydroxide-Pt nanoparticles as an inorganic nanocomposite and potentate anodic material for methanol electrooxidation in alkaline media by Habibi \& Ghaderi. They found that the PtNPs/Ni-Al LDH/GCE exhibited higher electrocatalytic activity than PtNPs/GCE and Ni-Al LDH/GCE. The second article focused on the nanomaterial was published by Hosseini \& Saeedi that was photocatalytic degradation of methyl orange on $\mathrm{Bi}_{2} \mathrm{O}_{3}$ and $\mathrm{Ag}_{2} \mathrm{O}-\mathrm{Bi}_{2} \mathrm{O}_{3}$ nano-photocatalysts. Incorporation of $\mathrm{Ag}_{2} \mathrm{O}$ in the structure of composite caused decreasing band gap and its response to visible light. Because a high percentage of sunlight is visible light, hence the $\mathrm{Ag}_{2} \mathrm{O}-\mathrm{Bi}_{2} \mathrm{O}_{3}$ nano-composite could be used as an efficient visible light driven photocatalyst for degradation of dye effluents by sunlight. Another nanocatalyst was studied by Ahmad et al. concerning synthesis and characterization of pure and nano-Ag impregnated chitosan beads and determination of catalytic activities of nano-Ag. They found that the nano-Ag as a reliable and active catalyst which made $\mathrm{NaBH}_{4}$ quite capable for the nitro reduction. Moreover, the catalytic activities of crosslinked chitosan substrate were found more reproducible as compared to the uncrosslinked substrate.

Other articles focused on the catalytic soot elimination environmentally were published by Kobayashi \& Hikosaka as well as Dhal et al. The former researcher group studied analyzing loose contact oxidation of diesel engine soot and $\mathrm{Ag} / \mathrm{CeO}_{2}$ catalyst using nonlinear regression analysis (Kobayashi \& Hikosaka). They found that the loose contact activity was depended on the condition of the carbon black particles, such as the bulkiness and physical contact with catalyst, and these can change depending on the mixing time used in the preparation procedure, with a long mixing time giving a result that approached the catalytic activity of the tight contact sample. Meanwhile, the later group investigated simultaneous elimination of soot and NOX through silver-barium based catalytic materials (Dhal et al.). They found that the catalysts were active in soot combustion with an indicative decrease of oxidation onset temperature compared to uncatalyzed soot oxidation. It has also been found that the Ag-based samples were able to simultaneously remove soot and NOX. In particular, the Ba-containing systems exhibited higher NOX storage capacity than Sr-catalyst. An adverse effect of soot on the NOX storage activity has been also observed. 
There are three articles which focused on the novel catalyst for fuel processing. The first article was focused on the preparation of biofuel from palm oil catalyzed by ammonium molybdate in homogeneous phase investigated by Sadighi \& Targhi. They suggested that the activity test confirms that the bio-naphtha produced from the proposed method has a few aromatic components, and its sulfur content was negligible. The cetane index reached 66.3 and suitable fuel for diesel engines vehicles. Another group, Luchters et al., studied the variability of data in high throughput experimentation for catalyst studies in fuel processing. They found that the ICP analysis indicated that loadings of both $\mathrm{Pt}$ and $\mathrm{Rh}$ were performed accurately through incipient wetness impregnation using the synthesis robot. In addition, CO chemisorption experiments of the Pt catalysts suggest equal active metal distribution on the alumina support. The reproducibility of the WGS and SMR reaction were assessed with both one-to-many and many-to-many experiments.

Other studies were focused on catalytic reduction process (Makama et al., Faten et al., and Cai et al.). Makama and coworkers suggested photo-catalytic reduction of aqueous $\mathrm{Cr}(\mathrm{VI})$ with $\mathrm{CdS}$ under visible light irradiation. They found that the nanoparticle size has a dramatic effect on the adsorption and reduction of $\mathrm{Cr}(\mathrm{VI})$. The results evidenced the inverse relationship between the apparent reduction rate constant and the CdS particle size. Another article, Faten and co-workers investigated characterization and application of aluminum dross as catalyst in pyrolysis of waste cooking oil. They suggested that an efficient catalyst derived from industrial solid waste was modified by acid washing for using in a pyrolysis of waste cooking oil. The modification of aluminum dross resulted in increased surface area, acidity, and thermal stability. Cai and coworkers suggested one-pot synthesis of $\mathrm{Bi} / \mathrm{Fe}_{3} \mathrm{O}_{4}$ and its catalytic performances for 4-nitrophenol reduction. They found that the $\mathrm{Bi} / \mathrm{Fe}_{3} \mathrm{O}_{4}$ composite was the bismuth particles were well dispersed. The catalyst has higher activity when $\mathrm{Bi} / \mathrm{Fe}$ molar ratio is 1:4 in the composite and the rate constant $k$ is about $0.611 \mathrm{~min}^{-1}$. The catalyst has good reusability which can be used 10 cycles without obvious deactivation. Furthermore, the catalyst can be easily separated by an external magnetic field.

Various novel catalysts were also found by some researchers. Pawar and co-workers studied modification, characterization, and catalytic application of mesolite for one pot synthesis of 3-methyl4-arylmethylene-isoxazol-5(4H)-ones. They concluded that modified dealuminated mesolite showed an efficient catalytic activity for the synthesis, via one pot three components condensation of benzaldehyde, ethylacetoacetate and hydroxylamine hydrochloride. The present method offered several advantages over the reported methods like a simple and inexpensive modification of catalyst, mild reaction condition, easy separation of catalyst, simple work-up procedure, nonchromatographic isolation and purification desired product and excellent yield. Janaun and coworkers investigated preparation and characterization of sugar based catalyst on various supports. They suggested that among the catalysts, the sulfonated carbon-base catalysts that were attached on the ceramic support exhibited the highest acidity followed by the catalyst deposited on the glass and aluminum supports. The porous structure of a ceramic surface, allowed a better interaction between reactants and $-\mathrm{SO}_{3} \mathrm{H}$ site in the carbon. Nurhadi focused on modification of coal char-loaded $\mathrm{TiO}_{2}$ by sulfonation and alkylsilylation to enhance catalytic activity in styrene oxidation with hydrogen peroxide as an oxidant. He found that the alkyl silylation could enhance the catalytic activity of $\mathrm{Ti}-\mathrm{SO}_{3} \mathrm{H} / \mathrm{CC}$ $600(2.0)$. High catalytic activity and reusability of the o-Ti-SO ${ }_{3} \mathrm{H} / \mathrm{CC}-600(2.0)$ were related to the modification of local environment of titanium active sites and the enhancement the hydrophobicity of catalyst particle by alkyl silylation. Another one is Li-Hua and coworkers which focused on synthesis, structural characterization and catalytic activity of a $\mathrm{Cu}$ (II) coordination polymer constructed from 1,4-phenylenediacetic acid and 2,2'-bipyridine. They found that the $\mathrm{Cu}$ (II) complex catalyst has good catalytic activity with a maximum yield of $54.3 \%$ and stability due to each $\mathrm{Cu}$ (II) atom adopts sixcoordination and forms a distorted octahedral configuration.

An article focusing the novel reactor design was published by Nur and coworkers concerning an evaluation of novel integrated dielectric barrier discharge plasma reactor as ozone generator. This paper presented a characterization of an integrated ozone generator constructed by seven of reactors 
of dielectric barrier discharge plasma (DBDP). They found that ozone concentration increased with the applied voltage, but in contrary, the concentration decreased with the flow rate of dry air. The higher ozone capacity can be produced with higher input power, but lower efficiency. The effect of dry air flow rate and applied voltage on ozone concentrations have been studied.

Currently, Bulletin of Chemical Reaction Engineering \& Catalysis journal is an open access international journal under licensed a Creative Commons Attribution-ShareAlike 4.0 International License (CC-by-SA). Therefore, readers can read and download any full-text articles for free of charge. Official website address of BCREC journal is: http://bcrec.undip.ac.id or http://bcrec.id. The Editor would like to appreciate and to call for papers all researchers, academicians, industrial practitioners focused on chemical reaction engineering and catalysis to contribute to this international journal.

Semarang, Indonesia, April 2017

\section{Istadi (Editor-in-Chief)}

Department of Chemical Engineering, Diponegoro University

E-mail: istadi@che.undip.ac.id 